Sharif University of Technology
Scientia Iranica
Special Issue on: Socio-Cognitive Engineering
I RAN I C A

Research Note

\title{
Case based reasoning for green information systems infusion and assimilation among IT professionals in university campuses
}

\author{
B. Anthony Jnr.*, M. Abdul Majid, and A. Romli \\ Faculty of Computer Systems \& Software Engineering, Universiti Malaysia Pahang Lebuhraya Tun Razak, 26300 Gambang, Pahang, \\ Malaysia.
}

Received 18 March 2017; received in revised form 5 May 2018; accepted 23 June 2018

\author{
KEYWORDS \\ Sustainability; \\ Green IS; \\ Case based reasoning; \\ University campuses; \\ Green IS \\ determinants; \\ Green IS lifecycle; \\ Decision support.
}

\begin{abstract}
Information Technology (IT) usage in university campuses consumes an enormous amount of power and incurs other costs in cooling and related operations. Currently, universities are infusing environmentally friendly initiatives in their campuses. However, IT professionals in most universities are not still sure how to infuse and assimilate environmentally friendly practices. Hence, green Information Systems (IS) are suggested for the utilization of technologies and systems in a greener and more sustainable planet. Accordingly, this study provides a review of existing green IS practices and further proposes a decision support framework based on Case Based Reasoning (CBR) technique. The proposed framework utilizes CBR to support the decision making of IT professionals in infusing and assimilating green IS within university campuses. Findings of this study show how the framework utilizes CBR to support IT professionals in assimilating green IS lifecycle and infusing green IS determinants. Furthermore, they show how IT professionals can green their university campuses. Moreover, this research study would be of interest to data and knowledge management community as well as environmental scientists and sustainability researchers.
\end{abstract}

(C) 2019 Sharif University of Technology. All rights reserved.

\section{Introduction}

In the year 2015, representatives from 195 countries participated in the United Nations (UN) climate change conference held in Paris, France. They unanimously agreed on the objective of limiting global warming to $1.5^{\circ} \mathrm{C}$ throughout the next decades [1] The recurrent and pervasive agenda for taking more

\footnotetext{
*. Corresponding author.

E-mail addresses: bkanjr@gmail.com (B. Anthony Jnr.); mazlina@ump.edu.my (M. Abdul Majid); awanis@ump.edu.my (A. Romli).
}

doi: $10.24200 /$ sci. 2018.20600 environmental care requires professionals, university institutions, enterprises, and the society to change their behavior and attitude towards the environment by paying attention to the natural environment and its limited resources. The change must occur in the society, individual, and enterprise levels [2]. The contribution and role of Information Systems (IS) in sustainability have become the concern of IS practitioners.

Accordingly, IS academicians around the world have begun to look seriously at the role IS can play in both creating and decreasing environmental effects. As a result, green IS has been proposed. Green IS involves the usage of IT infrastructure and computer facilities in a more effective and environmentally responsible manner [3]. Hence, it can be infused in university 
campuses through a collection of tactical and strategic initiatives to reduce energy usage and the carbon footprint of universities' IT infrastructure operation.

Presently, Information Technology (IT) professionals find it difficult to infuse environmentally friendly strategies in their institutional processes. Thus, infusing green practice requirements is often unmet and IT professionals have to rely on incomplete or inconsistent information and implement green IS based on their own personal experience [4]. Therefore, IT professionals in university campuses are not able to adopt green initiatives effectively. This is attributed to inadequate availability of updated, high quality information and unsuitable techniques to support the decision making process [5]. Although there are several approaches that have been developed to assist IT professionals in going green, e.g., ISO 14001 environmental management system, which aims to measure the environmental impacts, they are complex and difficult to adopt by IT professionals. Thus, there is need for a less sophisticated approach to implementing environmental friendly practices that can provide quick solutions and are easy to apply by IT professionals in university campuses [6].

Over the years, several techniques, such as fuzzy logic, software agents, analytic hierarchy process, etc., have been developed to support green practices in various domains. This study suggests the application of Case Based Reasoning (CBR) as a technique to support decision making of IT professionals in university campuses by providing information on how IT professionals can infuse and assimilate green IS practices. Moreover, CBR is selected as the technique to facilitate greening IS for ensuring that the IT professional considers the social, environmental, and economic impacts of IT usage in the university campus. Besides, CBR can help the IT professional propose solutions to deploying IT infrastructure in caring for the environment, reducing economic cost, and considering the society.

Therefore, this study provides a review of how CBR can provide support for the IT professional in infusing and assimilating green IS practices to support environmentally friendly practices in university campuses. The structure of this paper is organized as follows: Section 2 presents the materials and methods. Section 3 provides the results. Section 4 gives the discussion. Finally, Section 5 is devoted to conclusion.

\section{Materials and methods}

\subsection{Overview of case based reasoning technique}

$\mathrm{CBR}$ is a division of Artificial Intelligence (AI), which is an approach based on using past experience in decision making and resolving problems, searching for the solutions to new problems using previously resolved

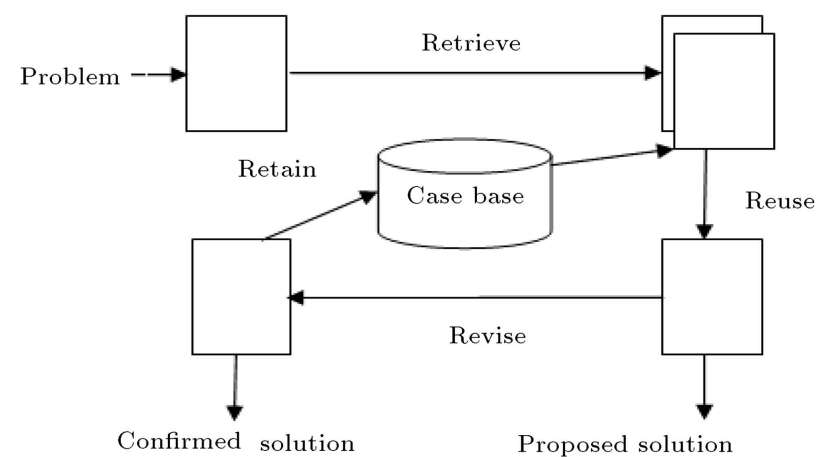

Figure 1. Typical CBR procedure [10].

difficulties, and reusing the existing solutions in new conditions [7]. This technique is similar to problem solving, which compares new cases with the previously indexed cases. CBR deploys a mixed qualitative and quantitative mixed approach for storage and retrieval of best practices [8].

In addition, the exceptional feature of CBR is that it does not need to match the query of IT professionals precisely, e.g., in searching problems [9]. The simple theory of CBR is that similar problems have similar solutions, even if the case base does not contain a solution that directly resolves the problem of the IT professional [9]. A solution can be obtainable for use as a starting point. Then, similar solutions can be adopted to provide some suggestions and recommendations to guide IT professionals. Furthermore, CBR comprises domain expert knowledge, a case base of past experiences, and a similarity measure for searching similar cases [10]. CBR technique is deployed in four steps as shown in Figure 1.

Figure 1 shows a typical CBR approach utilized to retrieve a similar past case to solve the new problem. The phases comprise: (a) retrieving, in which an assumed specific problem retrieves cases similar to the case base to solve the new problem [7]; (b) reusing, which involves selecting the possible solutions from the retrieved cases [8]. If the solutions are not suitable to use straight away, they may be adapted to the new situation; (c) revising, which comprises changing existing solution to the target problem [9]. It also involves testing the new solution to the problem and, if needed, it continues to revise [10]; (d) retaining, which stores the resultant new cases in the case base if the solution has effectively been applied to the target problem [8].

\subsection{Related studies on existing techniques}

Presently, a few techniques are utilized in different domains to infuse and assimilate green strategies. These techniques have been utilized by researchers to support enterprises in reducing water consumption, energy utilization, and cost. They include agent based technology, which was integrated by Huang and 
Lin [11], Rogers et al. [12], Ciocoiu and Ciolac [13], and Rao and Jiang [14]. The researchers utilized agent based techniques to reduce energy consumption in organizational process. Similarly, fuzzy logic was applied as a technique by Bai and Sarkis [15] and Deng et al. [16] to assist management in making decisions on how to implement green strategies in organizations. SWOT analysis technique was adapted by Silva et al. [17] to evaluate the strengths, weaknesses, opportunities, and threats to organizations by adopting green IT in their enterprise.

Likewise, Belecheanu et al. [8] applied CBR for decision support in new product development. The authors believed that CBR could support design engineers and managers during the initial phases of original product development in a concurrent deployment environment. Also, Pawlish and Varde [5] adopted CBR to assist practitioners in university data centers in making decision on how to make campus data center green, thereby reducing energy consumption and $\mathrm{CO}_{2}$ emission. Anthony and $\mathrm{Pa}$ [2] developed a CBR architecture for green IS adoption in enterprise to educate, train, and support practitioners in applying green IS in their enterprise and to support them in implementing and attaining eco-sustainability objective.

Romli et al. [7] presented the development of an eco-CBR method for supporting green product design. Their method was intended to assist industrial professionals in attaining access to sustainable solutions for meeting the new product design requirements and features by reusing design solutions from similar cases. Wang et al. [18] proposed a case based model aimed at enabling retailing operation to go green. The case based model was developed through the use of CBR technology to assist the stakeholders and consumers in attaining a leading role within a green supply chain. Ghazalli and Murata [19] integrated Analytic Hierarchy Process (AHP) and CBR technique for assessing remanufacturing end of life choice strategy. However, the model was mostly concerned with the economic and environmental costs.

Kuo [20] provided an intelligent CBR-AHP decision support method for product recycling schemes. The researcher infused AHP to carry out evaluation of the recyclability index for a product and CBR to provide system designers with experiences from the past cases to carry out recycling activities. Jeong et al. [21] proposed an approximate Life Cycle Assessment (LCA) method using CBR for a rapid and convenient environmental evaluation in product development. This method assists system designers to attain eco-product development in their concurrent engineering processes.

Based on the findings from the reviewed studies, CBR has been applied in retailing operations, manufacturing, production, building, design, development, and organizational process. However, to the best of the authors' knowledge, CBR technique has not been utilized to support IT professionals in green IS assimilation and infusion in university institutions domain. Thus, the authors are motivated to carry out this research study to utilize CBR to support the decision making of IT professionals in assimilating and infusing green IS practices, initiatives, and strategies in university campus or institution domain. Also, the studies carried out up to now have not considered the green IS determinants; they only consider some of the green IS life cycles and techniques. Accordingly, the authors propose a framework to show the green IS determinants and life cycle to be considered by IT professionals in the assimilation and infusion of green IS.

\subsection{Green IS practice in university campuses}

Green IS is an evolving discipline and problems related to it are of emergent concern for the economic, environmental, and social impacts in the 21st century. Green IS is becoming an imperative topic to protect our future [2]. Lately, more specific focus on "greening" IS has been evident all over the world, as there has been an increase in assimilating green IS practices in universities across the world [15]. Green IS can have positive effects, including the ability to reduce global emissions and provide solutions to reducing energy usage and wastes generated by the use of IT hardware [1].

Therefore, over the years, there has been an exponential research in green IS domain; however, little research has been directed toward IT professionals in university domain. Among the studies, Nana et al. [22] analyzed the possible means of diffusing green strategies by educational institutions in order to ensure that their campus environments were economically sustainable. Their research aimed to further proliferate awareness of the advantages and limitations of green practices in Ghana. In addition, Mishra et al. [23] contributed by presenting a green education study aimed at revising few recent green IT curricula in prominent universities. McGibbon and Van Belle [24] examined how universities could accomplish sustainable campus operations by assimilating sustainability in teaching and research. They provided an understanding of how people, operating system, processes, and technology could work together to support sustainability objectives in universities.

Tedre et al. [25] researched on the integration of environmental initiatives in IT education in Tanzania. The authors aspired to raise responsiveness of students to environmental issues by IT usage through providing knowledge on existing laws and regulations across the world. The authors went further to equip students with knowledge and tools for making cognizant choices concerning IT deployment. McGibbon and Van Belle [26] 
provided the method of incorporating environmental sustainability initiatives into the curriculum of University of Cape Town by infusing the problem of project based learning to lessen $\mathrm{CO}_{2}$ at the university, since there was lack of legislative pressure or environmental regulatory in the country.

Recently, many universities have started to introduce green strategies, since it has been argued that green IS is promising to be influential in reducing the negative environmental effects of the swiftly developing economies in the world [27]. Thus, it is observable that the goals of the green IS in university are to reduce the use of harmful materials found in computer systems, to capitalize on the product lifetime, and to support biodegradability and recyclability of obsolete and campus generated waste products [28]. IT professionals are expected to contribute substantially by introducing green IS strategies to the university at large. This can be carried out by developing the required capabilities that will support and lead sustainable initiatives in the campus [2]. Although climate change is seen as one of the greatest issues of our time, academicians, in general, and scholars in IS, in particular, have been slow to embrace this as a research domain of urgency. This paper is thus a call for the discipline of IS to make a better world and respond directly to the call for resolving global challenges to ensure the consideration for social and environmental concerns.

\section{Results}

This study synthesizes and extracts secondary data from existing literature on green IS and green IT practices in enterprise and institutions. This section discusses how green IS can be assimilated and infused in university campuses by presenting the proposed framework developed from prior studies.

\subsection{Developed framework}

The persistent deployment of IT infrastructure places an increasing concern on the climate. Correspondingly, IT professionals in university institutions are plagued with the task of reducing energy utilization and lessening the cost of IT operation. However, presently, they lack the capability to make decisions on how to assimilate and infuse green practices in their institutional processes. Figure 2 shows the developed framework facilitated by a technique proposed to support IT professionals in making decision on infusing and assimilating green IS practices in university campuses.

Figure 2 depicts the developed framework to assist IT professionals in reducing $\mathrm{CO}_{2}$ emission by the use of IT infrastructures and facilities in the campus, lessening natural resources consumption, and decreasing water wastage. Hence, IT professionals can effectively adopt the framework to decrease energy usage and the cost incurred by utilizing IT infrastructures, thereby reducing the electricity bill of the university.

The framework comprises four modules. The first one is the green IS determinants, which influences the green IS infusion and assimilation. The green IS determinants include people, management, IT infrastructures, pressure, IT strategy, and information availability. They are important for IT professionals in assimilating green IS practices in the institutional processes. The second module is green IS life cycle, which is the current process implemented in the university and influences green IS infusion and assimilation. This module is important because IT professionals need to infuse all the stated processes to attain the

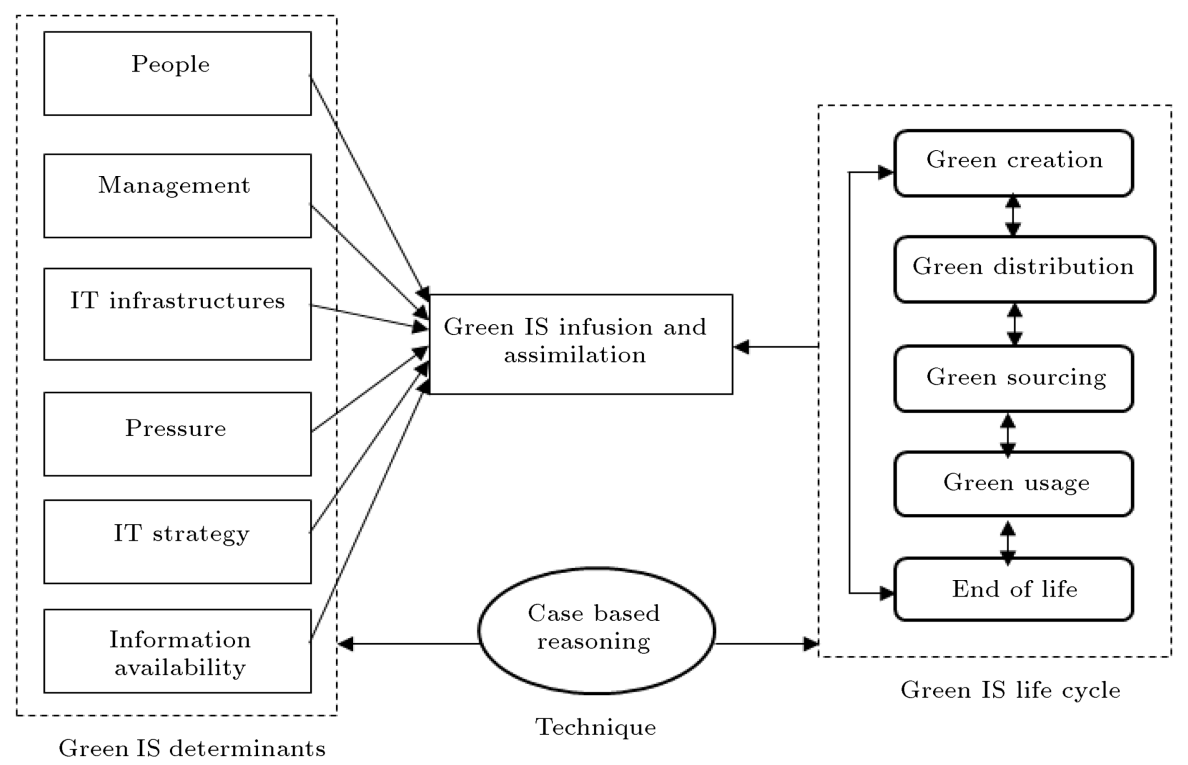

Figure 2. Designed framework for green IS assimilation and infusion. 
status of a green campus. Hence, each of the processes must be implemented; the processes include creation, distribution, sourcing, usage, and end of life.

The third module is "green IS infusion and assimilation," which is the main target of IT professionals to infuse and assimilate green IS practices in their institutional operations. As seen, this module is influenced by the green IS determinants and life cycle. Correspondingly, the last module is case base reasoning, which is the technique integrated to support IT professionals in infusing the green IS life cycle and assimilating the green IS determinants. The green IS determinants and life cycle are discussed in the next sub-section

\subsubsection{Green IS determinants}

This section discusses the green IS determinants presented in the developed framework. Accordingly, "people" includes IT professionals, employees, staff, individuals, society, and IT human infrastructure in the university that infuses and assimilates green IS practices [4]. People commitment is required in planning deploying and implementing campus system with the environmental deliberations in mind [3]. Thus, people's actions can influence how green practices are infused and assimilated to achieve sustainability in their university [1].

The next determinant is management that defines the administrative decision making (roles, responsibilities, accountability, and control) of green IS initiatives [23]. Moreover, this variable comprises guiding sustainability principles of information systems usage in daily operations of the university [26]. Besides, management offers a medium for defining the campus process. It is the operating pillar that defines the administration of green initiatives in the university [29]

The next determinant is IT infrastructure, which comprises technologies, systems, and IT facilities deployed to support operations of the university [1]. IT infrastructure includes the network-critical physical infrastructure such as ventilating, cooling, and power delivery and communications technologies such as network devices, physical servers, and shared services [4]. Thus, the technologies used in the university will influence green IS practice.

Pressure influences the decision making of universities in infusing green IS practices [30,31]. Pressure may begin with increasing energy costs, requiring IT professionals to lessen power consumption of IT hardware [32,33]. On the contrary, lowering energy costs is often associated with the aim of achieving economic advantage. Another source of pressure is governmental associations who stipulate environmental standards and regulations enforced towards preserving the natural environment from industrial pollution and damage [34,35]. Lastly, there is also the issue of social pressure from the cumulative community call for green solutions and the increased positive society awareness of green initiatives [36,37].

IT strategy is another determinant, which refers to the current strategy implemented in the university in relation to green IS initiatives. Hence, IT strategy mainly involves depiction of the university in terms of its routine, scope, and management structure [31,34]. This determinant determines how IT professionals implement their institutional strategies. Therefore, the strategy adopted by IT professionals to accomplish objectives of the university is very important in infusing and assimilating green IS practices [38,39]. Moreover, IT strategy further aims to support decrease in campus operating expenses incurred by deploying IT infrastructure $[40,41]$.

Information availability is another determinant that comprises the dissemination of information on how IT professionals can infuse green IS practices within the university campus [42]. Hence, development of universities toward making them green cannot be successfully undertaken without specific information provided through an established green knowledge source [38]. Thus, lack of information can hinder the university from improving environmental performance of its campus [43].

\subsection{Green IS life cycle}

This section briefly explains each of the green IS life cycles presented in the developed framework. Green creation refers to the role of IS in supporting environmental initiatives of the university [40]. It is implemented when IT professionals systematically utilize IS in their institutional process, carbon foot print analysis, and ecological management in the production and development activities [44]. Moreover, it also encompasses IT based low $\mathrm{CO}_{2}$ solutions such as IP telephony, telecommuting, web based campus services, thin client, virtual collaboration, and videoconferencing [45].

Green distribution involves the deployment of systems with automated components, computers, and other auxiliary subsystems with limited impact on the environment [46]. This phase emboldens operative processes and increases the reutilization and reuse proportion of developed products. Additionally, this phase involves sterile delivery systems to encourage minimal unwanted materialization, which increases the competence of campus, thereby lowering resource consumption [47].

Green sourcing entails the practice of purchasing only environmentally friendly preferable IT infrastructures with green labels [40]. This practice involves ecofriendly procurement practices for IT hardware and services using green IS initiatives that focus on the environmental assessment and auditing of suppliers and 


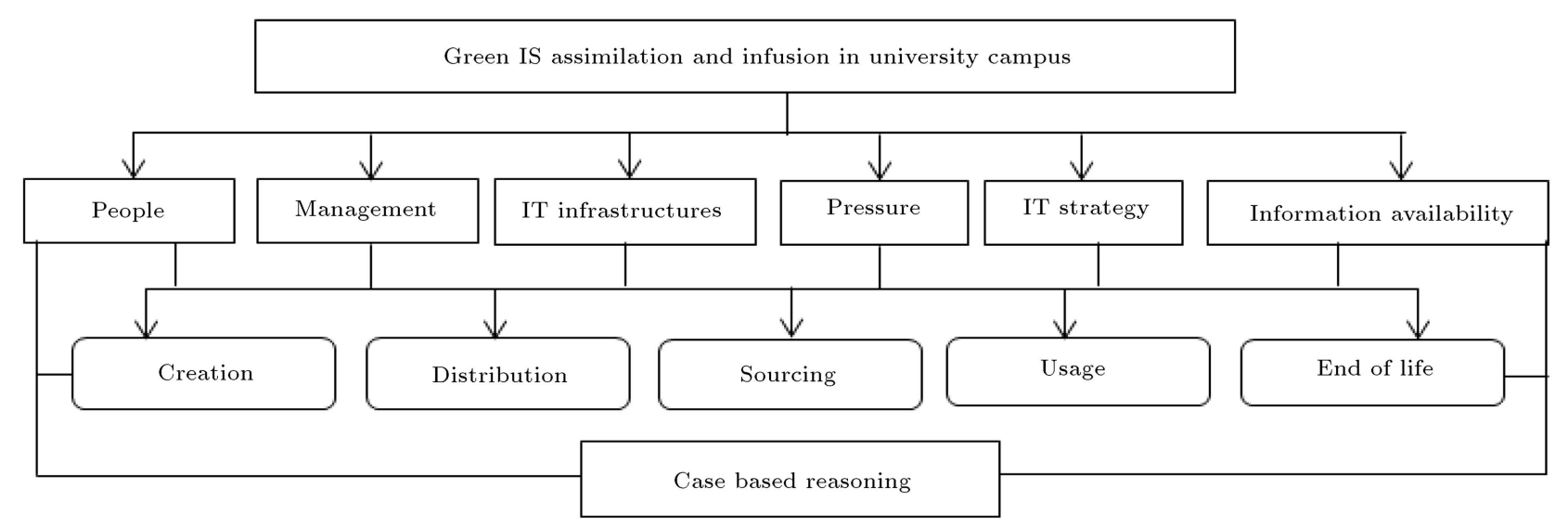

Figure 3. Dependent variable flow.

the selection of IT hardware and services according to predefined environmental criteria [41,42]. Furthermore, green sourcing refers to ecological purchasing, consisting of activities that include the recycling, reuse, and reduction of materials in the practice of purchasing $[2,43]$.

Correspondingly, green usage includes reducing IT induced CO2 emissions and deployment of IT equipment that consumes low energy. This practice reduces installed power capacity and enhances energy efficiency in powering and cooling of IT assets of the university $[1,44]$. This process aims to decrease energy consumption by optimizing power utilization without decreasing the installed power base $[45,46]$. Lastly, end of life comprises practices that reduce ewaste by repairing, re-deploying, disposing, refurbishing, retaining, or reusing outdated IT hardware in an environmentally friendly manner $[47,48]$. This phase provides a flexible and concise administrative solution to gathering and re-processing of discarded redundant IT equipment by recycling electronic waste [49]. Besides, end of life practices reduce waste, minimize $\mathrm{CO}_{2}$ emissions, and control handling cost [50].

Figure 3 shows how case based reasoning is applied to green IS assimilation and infusion in the university campus. CBR aims to support IT professionals in making decisions on how to implement green IS initiatives in their institutional process.

Figure 3 shows how IT professionals can accomplish green IS facilitated by CBR, which is incorporated into the framework to provide the support needed by IT professionals in assimilating and infusing green IS practices in university campus. Moreover, CBR provides information on how IT professional can improve their current green IS practices.

\section{Discussion}

Global warming and other environmental issues such as resource and energy constraint are gradually be- coming the main concerns of the world and need to be addressed [51]. As a result, IT professionals in university campuses are currently contributing to reduce environmental issues [48]. However, the present approaches adopted by IT professionals do not provide knowledge on how they can infuse and assimilate green IS practices for environmental sustainability [12]. Thus, there is need for an approach that can guide, enlighten, and support IT professionals in adopting green IS practices. Therefore, this study developed a framework integrated with Case Base Reasoning (CBR) to support IT professionals in assimilating and infusing green IS initiatives. This study opted for CBR since, as one of the learning techniques used in Artificial Intelligence (AI), it has been used by several researchers, as reviewed in Section 2.2. CBR is a practical method that creates and uses database of old cases or problems to resolve new problems.

In CBR technique, knowledge is embodied in the form of experiences or cases, in which a case, as stated previously, is a theorized piece of knowledge representing an experience [50]. The principle of CBR technique is to recognize past cases very similar to a different problem and utilize experiences from them for resolving the new problem as represented in Figure 1. In this perspective, a case is a portion of knowledge representing an experience [18]. It can enclose past knowledge in relation to the content of the case and the context in which the knowledge can be infused or assimilated. Typically, a case comprises the problem that defines the state of the world when the case happened and the solution to that problem. Presently, IT professional are plagued with the difficulty to implement green IS initiatives. According to Kuo [20], the major concerns of IT professionals are related to the difficulty of making decision on infusion and assimilation of green IS practices.

CBR technique was integrated into the developed framework, because it provided similar green solutions to the new problem by finding a similar problem that 
was resolved in the past and using the same solution for the new green IS problem [19]. Besides, CBR was suitable for sustained incremental learning, since a new experience was attained whenever a problem was resolved, making it available for the later use by other IT professionals in the future [21]. Therefore, IT professionals could use past experiences for infusing and assimilating various green IS initiatives. This is because IT professionals vary in terms of information acquisition and competence seeking.

\section{Conclusion}

This study developed a framework to support IT professionals in making decision on assimilating and infusing green IS practices in university campuses towards addressing environmental issues. Although the prior studies, such as Nana et al. [22], Mishra et al. [23], McGibbon and Van Belle [24], Tedre et al. [25], and McGibbon and Van Belle [26] focused on developing models and frameworks to address green practice adoption in institutions, less attention was paid to integrating artificial intelligent techniques such as CBR for assimilating and infusing green IS practices in university campuses. Consequently, this study was aimed to develop a framework for assimilating and infusing green IS practices in university institutions aided by CBR technique.

The developed framework consisted of the determinants and life cycle, which were to be considered by IT professionals for infusing and assimilating green IS practices in their institutions. IT professionals could infuse the determinants and assimilate the life cycle in line with their institutional activities to make their university campus green. This work is one of the first research studies to integrate a technique, namely CBR, with the developed framework. Existing research studies only consider the determinants and/or life cycle. Besides, to the best of the authors' knowledge, no framework or model has been developed or proposed to support the decisions of IT professionals in university campuses to assimilate and infuse green practices assisted by a technique.

IT facilities usage promises many gains to university campuses. However, it is not without side effects, particularly environmental impacts, since IT has both negative and positive impacts in its use and production. Green IS practice needs to be infused and assimilated to reduce negative impacts and increase positive effects of IT in an approach that certifies the achievement of sustainable resource consumption. Moreover, IT professionals should be educated on how to employ green IS tools and services efficiently and effectively. This can be solved by IT professionals utilizing the developed framework presented in this research paper. In this regard, green IS has begun as an important tool that can be used to decrease the direct environmental effects of deployment, operation, usage, and disposing of computers, servers, and other supplementary subsystems.

Every research study has limitation(s) and this research is not an exception. The developed framework determinants and life cycle were only derived from the existing literature and were not verified statistically. Therefore, it is imperative to employ a survey questionnaire to validate determinants and life cycle of the framework. Moreover, CBR was only integrated into the model and its applicability to green IS practice was not presented. Therefore, in future works, the developed framework can be verified by conducting a survey study through using questionnaires to collect data from IT professionals of the selected university institutions in Malaysia to verify the determinants and life cycle derived from the literature. Moreover, the inter-relationships within the developed framework can empirically be validated.

\section{References}

1. Klör, B. "Understanding the role of decision support systems in green is research: literature review and research agenda", PACIS, p. 378 (2016).

2. Anthony, Jr. B. and Pa, N.C. "A case based reasoning architecture and component based model for Green IS implementation and diffusion in organisation", International Journal of Digital Information and Wireless Communications, 6(2), pp. 97-112 (2016).

3. Dalvi-Esfahani, M., Ramayah, T., and Rahman, A.A. "Moderating role of personal values on managers' intention to adopt green IS: Examining norm activation theory", Industrial Management \& Data Systems, 117(3), pp. 582-604 (2017).

4. Jr, B.A., Majid, M.A., and Romli, A. "Green information technology system practice for sustainable collaborative enterprise: a structural literature review", International Journal of Sustainable Society, 9(3), pp. 242-272 (2017).

5. Pawlish, M.J. and Varde, A.S. "A decision support system for green data centers", Proceedings of the 3rd Workshop on Ph.D. Students in Information and Knowledge Management, pp. 47-56 (2010).

6. Jr, B.A., Majid, M.A., and Romli A. "A Green information technology governance framework for ecoenvironmental risk mitigation", Progress in Industrial Ecology, an International Journal, 11(1), pp. 30-48 (2017).

7. Romli, A., Setchi, R., Soe, S., and Prickett, P. "Eco-case based reasoning (Eco-CBR) for supporting sustainable product design", 2nd International Conference on Sustainable Design and Manufacturing, Seville, pp. 1-12 (2015).

8. Belecheanu, R., Pawar, K.S., Barson, R.J., Bredehorst, B., and Weber, F. "The application of case based 
reasoning to decision support in new product development", Integrated Manufacturing Systems, 14(1), pp. 36-45 (2003).

9. Shen, Y., Colloc, J., Jacquet-Andrieu, A., and Lei, K. "Emerging medical informatics with case-based reasoning for aiding clinical decision in multi-agent system", Journal of Biomedical Informatics, 56(1), pp. 307-317 (2015).

10. Chang, J.W., Lee, M.C., and Wang, T.I. "Integrating a semantic-based retrieval agent into case-based reasoning systems: A case study of an online bookstore", Computers in Industry, 78(1), pp. 29-42 (2016).

11. Huang, J. and Lin, C. "Agent-based green web service selection and dynamic speed scaling", 20th International Conference on Web Services, pp. 91-98 (2013).

12. Rogers, K., Jenkin, T.A., Corbett, J., and Webster, J. "The effects of 'green' on IT/S projects: Recycling the garbage can model", 46th Hawaii International Conference on System Sciences, pp. 974-983 (2013).

13. Ciocoiu, N.C. and Ciolac, C.E. "Automated framework for Green IT classification using software agents", 2nd International Conference on Computer Science and Information Technology, pp. 279-283 (2009).

14. Rao, D. and Jiang, Z. "Auxiliary algorithms in green multi-agent planning framework", International Conference on Network Computing and Information Security, pp. 175-179 (2011).

15. Bai, C. and Sarkis, J. "Green information technology strategic justification and evaluation", Information Systems Frontiers, 15(5), pp. 831-847 (2013).

16. Deng, H., Molla, A., and Corbitt, B. "A fuzzy logic based green information technology readiness model", International Conference on Artificial Intelligence and Computational Intelligence, pp. 465-470 (2009).

17. Silva, L.C., Poleto, T., De Moura, J.A., Daher, S.D.F.D., and Costa, A.P.C. "Group decision approach to adopt Green IT practices based on SWOT analysis", International Conference on Systems, Man, and Cybernetics, pp. 747-751 (2013).

18. Wang, C., Vaughan, J., Mercer, J., and Zhao, Y. "A case-based model facilitating retailing operations going "green": A proposed research agenda with a consideration of recession", International Summer Conference of Asia Pacific Business Innovation and Technology Management, pp. 1-4 (2011).

19. Ghazalli, Z. and Murata, A. "Development of an AHPCBR evaluation system for remanufacturing: endof-life selection strategy", International Journal of Sustainable Engineering, 4(1), pp. 2-15 (2011).

20. Kuo, T.C. "Combination of case-based reasoning and analytical hierarchy process for providing intelligent decision support for product recycling strategies", Expert Systems with Applications, 37(8), pp. 55585563 (2010).
21. Jeong, M.G., Morrison, J.R., and Suh, H.W. "Approximate life cycle assessment using case-based reasoning for the eco design of products" International Conference on Automation Science and Engineering, pp. 486491 (2013).

22. Nana, Y.A., Amevi, A., and Nii, Q. "Encouraging green ICT implementation strategies in polytechnic education in Ghana", International Journal of Applied Information Systems, 10(6), pp. 14-21 (2016).

23. Mishra, A., Yazici, A., and Mishra, D. "Green information technology/information system education: Curriculum views", TTEM, 7(3), pp. 679-686 (2012).

24. McGibbon, C. and Van Belle, J.P. "Integrating environmental sustainability issues into the curriculum through problem-based and project-based learning: a case study at the University of Cape Town", Current Opinion in Environmental Sustainability, 16(1), pp. 81-88 (2015).

25. Tedre, M., Chachage, B., and Faida, J. "Integrating environmental issues in IT education in Tanzania", 39th IEEE Frontiers in Education Conference, pp. 1-7 (2009).

26. McGibbon, C. and Van Belle, J.P. "Integrating green information systems into the curriculum using a carbon footprinting case", European Conference on Information Management and Evaluation, p. 104 (2013).

27. Omarov, R., Abdygaliyeva, S., Omar, D., and Kunelbayev, M. "Integrated system for the use of solar energy in animal farm", Scientia Iranica, Transactions D, Computer Science \& Engineering, Electrical, 24(6), pp. 3213-3222 (2017).

28. Simab, M., Chatrsimab, S., Yazdi, S., and Simab, A. "Using integrated method to rank the power system contingency", Scientia Iranica. Transactions D, Computer Science \& Engineering, Electrical, 24(3), pp. 1373-1383 (2017).

29. Cooper, V. and Molla, A. "Information systems absorptive capacity for environmentally driven ISenabled transformation", Information Systems Journal, 27(4), pp. 379-425 (2017).

30. Jnr, B.A., Majid, M.A., and Romli, A. "A descriptive study towards green computing practice application for data centers in IT based industries", MATEC Web of Conferences, 150(1) pp. 1-8 (2018).

31. Dao, V., Langella, I., and Carbo, J. "From green to sustainability: Information Technology and an integrated sustainability framework", The Journal of Strategic Information Systems, 20(1), pp. 63-79 (2011).

32. Jnr, B.A., Majid, M.A., and Romli, A. "A proposed model for green practice adoption and implementation in information technology based organizations", Problemy Ekorozwoju-Problems of Sustainable Development, 13(1), pp. 95-112 (2018).

33. Loeser, F., Recker, J., Brocke, J.V., Molla, A., and Zarnekow, R. "How IT executives create organizational benefits by translating environmental strategies into 
Green IS initiatives", Information Systems Journal (2017).

34. Jnr, B.A., Majid, M.A., and Romli, A. "Application of intelligent agents and case based reasoning techniques for green software development", TTEM, 12(1), pp. 30-43 (2017).

35. Molla, A., Abareshi, A., and Cooper, V. "Green IT beliefs and pro-environmental IT practices among IT professionals", Information Technology \& People, 27(2), pp. 129-154 (2014).

36. Ngo, A.T., West, G.E., and Calkins, P.H. "Determinants of environmentally responsible behaviours for greenhouse gas reduction". International Journal of Consumer Studies, 33(2), pp. 151-161 (2009).

37. Radu, L.D. "Determinants of green ICT adoption in organizations: A theoretical perspective", Sustainability, 8(8), pp. 1-16 (2016).

38. Jnr, B.A., Majid, M.A., and Romli, A. "An empirical study on predictors of green sustainable software practices in Malaysian electronic industries", Journal of ICT, 18(2), pp. 347-391 (2018).

39. Deng, Q. and Ji, S. "Organizational green IT adoption: concept and evidence", Sustainability, 7(12), pp. 16737-16755 (2015).

40. Ainin, S., Naqshbandi, M.M., and Dezdar, S. "Impact of adoption of Green IT practices on organizational performance", Quality \& Quantity, 50(5), pp. 19291948 (2016).

41. Cooper, V.A. and Molla, A. "Absorptive capacity and contextual factors that influence green IT assimilation", Australasian Journal of Information Systems, 18(3), pp. 271-288 (2014).

42. Butler, T. "Compliance with institutional imperatives on environmental sustainability: Building theory on the role of Green IS", The Journal of Strategic Information Systems, 20(1), pp. 6-26 (2011).

43. Watson, R.T., Boudreau, M.C., Chen, A.J., and Sepúlveda, H.H. "Green projects: An information drives analysis of four cases", The Journal of Strategic Information Systems, 20(1), pp. 55-62 (2011).

44. Anthony, B., Majid, M.A., and Romli, A. "An agent based Green assessment system architecture for sustainable practice implementation among IT practitioners in university campuses", 8th International Conference on Information Technology, pp. 17-25 (2017).

45. Raza, K., Patle, V.K., and Arya, S. "A review on green computing for eco-friendly and sustainable IT", Journal of Computational Intelligence and Electronic Systems, 1(1), pp. 3-16 (2012).

46. Murugesan, S. "Harnessing green IT: Principles and practices", IT Professional, 10(1), pp. 24-33 (2008).
47. Saha, B. "Green computing", International Journal of Computer Trends and Technology, 14(2), pp. 46-50 (2014).

48. Ninlawan, C., Seksan, P., Tossapol, K., and Pilada, W. "The implementation of green supply chain management practices in electronics industry", Proceedings of the International Multiconference of Engineers and Computer Scientists, pp. 17-19 (2010).

49. Saha, B. "Green computing", International Journal of Computer Trends and Technology, 14(2), pp. 46-50 (2014).

50. Anthony, B. and Majid, M.A. "An agent based green decision making model for sustainable information technology governance", Advanced Science Letters, 23(11), pp. 11114-11118 (2017).

51. Gong, D.C., Chen, P.S., and Lu, T.Y. "Multi-objective optimization of green supply chain network designs for transportation mode selection", Scientia Iranica, Transactions E, Industrial Engineering, 24(6), pp. 3355-3370 (2017).

\section{Biographies}

Bokolo Anthony Jnr. is currently a Research Fellow in the Faculty of Computer Systems and Software Engineering, Universiti Malaysia Pahang. He has MSc degree in Computer Science from Universiti Putra Malaysia. He currently works in the field of research and development, and has published several papers. His research interest includes sustainability attainment, green IT/IS, software management, risk assessment and mitigation, IT governance, collaborative enterprise, software agents, and knowledge management.

Mazlina Abdul Majid is currently an Associate Professor of Computer Science in the Faculty of Computer Systems and Software Engineering, Universiti Malaysia Pahang. She received the $\mathrm{PhD}$ degree in Computer Science from University of Nottingham, UK, in 2011. Her current research areas include discrete event and agent based simulation, human behavior modelling, and human-computer interaction.

Awanis Romli is currently a senior lecturer of Computer Science in the Faculty of Computer Systems and Software Engineering, Universiti Malaysia Pahang. She received the $\mathrm{PhD}$ degree from Cardiff University, UK, in 2015. Her research interests include sustainability, case based reasoning, engineering management, and decision support systems. 